\title{
Glucagon-Like Peptide-I Receptor Activation in the Ventral Tegmental Area Decreases the Reinforcing Efficacy of Cocaine
}

\author{
Heath D Schmidt*,1,2,4, Elizabeth G Mietlicki-Baase ${ }^{3,4}$, Kelsey Y Ige', John J Maurer', David J Reiner ${ }^{3}$, \\ Derek J Zimmer ${ }^{3}$, Duncan S Van Nest', Leonardo A Guercio', Mathieu E Wimmer', Diana R Olivos ${ }^{3}$, \\ Bart C De Jonghe ${ }^{2}$ and Matthew R Hayes ${ }^{2,3}$ \\ 'Center for Neurobiology and Behavior, Department of Psychiatry, Perelman School of Medicine, University of Pennsylvania, Philadelphia, PA, USA; \\ ${ }^{2}$ Department of Biobehavioral Health Sciences, School of Nursing, University of Pennsylvania, Philadelphia, PA, USA; ${ }^{3}$ Translational Neuroscience \\ Program, Department of Psychiatry, Perelman School of Medicine, University of Pennsylvania, Philadelphia, PA, USA
}

\begin{abstract}
Cocaine addiction continues to be a significant public health problem for which there are currently no effective FDA-approved treatments. Thus, there is a clear need to identify and develop novel pharmacotherapies for cocaine addiction. Recent evidence indicates that activation of glucagon-like peptide- I (GLP-I) receptors in the ventral tegmental area (VTA) reduces intake of highly palatable food. As the neural circuits and neurobiological mechanisms underlying drug taking overlap to some degree with those regulating food intake, these findings suggest that activation of central GLP-I receptors may also attenuate cocaine taking. Here, we show that intra-VTA administration of the GLP-I receptor agonist exendin-4 (0.05 $\mu \mathrm{g})$ significantly reduced cocaine, but not sucrose, self-administration in rats. We also demonstrate that cocaine taking is associated with elevated plasma corticosterone levels and that systemic infusion of cocaine activates GLP-Iexpressing neurons in the nucleus tractus solitarius (NTS), a hindbrain nucleus that projects monosynaptically to the VTA. To determine the potential mechanisms by which cocaine activates NTS GLP-I-expressing neurons, we microinjected corticosterone $(0.5 \mu \mathrm{g})$ directly into the hindbrain fourth ventricle. Intraventricular corticosterone attenuated cocaine self-administration and this effect was blocked in animals pretreated with the GLP-I receptor antagonist exendin-(9-39) $(10 \mu \mathrm{g})$ in the VTA. Finally, AAV-shRNA-mediated knockdown of VTA GLP-I receptors was sufficient to augment cocaine self-administration. Taken together, these findings indicate that increased activation of NTS GLP-I -expressing neurons by corticosterone may represent a homeostatic response to cocaine taking, thereby reducing the reinforcing efficacy of cocaine. Therefore, central GLP-I receptors may represent a novel target for cocaine addiction pharmacotherapies.

Neuropsychopharmacology (2016) 4I, 1917-1928; doi:I0.1038/npp.2015.362; published online 23 March 2016
\end{abstract}

\section{INTRODUCTION}

The reinforcing effects of cocaine are primarily dependent upon activation of the mesolimbic dopamine system (Pierce and Kumaresan, 2006). Dopaminergic projections from the ventral tegmental area (VTA) to forebrain structures including the nucleus accumbens (NAc) play a critical role in cocaine taking and seeking (Schmidt et al, 2005). In addition to regulating drug taking, dopamine projections from the VTA to the NAc also influence food intake (Kenny, 2011b; Narayanan et al, 2010). Indeed, studies of the neurobiological mechanisms underlying motivated feeding behavior have informed much of the basic research investigating neural substrates of drug addiction (Kenny, 2011a).

\footnotetext{
*Correspondence: Dr HD Schmidt, Department of Biobehavioral Health Sciences, School of Nursing, Department of Psychiatry, Perelman School of Medicine, University of Pennsylvania, 125 South 31 st Street, Philadelphia, PA 19104, USA, Tel: + I 215573 829|, Fax: + I 215573 7605, E-mail: hschmidt@nursing.upenn.edu

${ }^{4}$ The first two authors contributed equally to this work.

Received 23 June 2015; revised II December 20I5; accepted II December 2015; accepted article preview online 17 December 2015
}

Glucagon-like peptide-1 (GLP-1), an incretin hormone released predominantly from $\mathrm{L}$ cells of the small intestine and neurons in the nucleus tractus solitarius (NTS) of the caudal brainstem (Grill and Hayes, 2012; Holst, 2007), is essential for the normal control of food intake in both humans (Gutzwiller et al, 1999a,b) and animal models (Barrera et al, 2011; Turton et al, 1996). Activation of GLP-1 receptors produces a number of physiological responses including enhanced insulin secretion, inhibition of gastric emptying, and reduced food intake (Hayes et al, 2010; Holst, 2007; Kanoski et al, 2011; Lovshin and Drucker, 2009; Ruttimann et al, 2009). Based on their roles in regulating blood glucose levels, food intake, and body weight, GLP-1 receptor (GLP-1R) agonists are FDA approved for the treatment of type 2 diabetes mellitus (Lovshin and Drucker, 2009) and obesity (Shukla et al, 2015).

Emerging evidence indicates that GLP-1R agonists reduce food intake, in part, by direct activation of GLP-1Rs expressed in the brain (Kanoski et al, 2011; Secher et al, 2014; Sisley et al, 2014). Of interest to the drug addiction field is the growing body of research showing that GLP-1, like many metabolic endocrine factors, regulates feeding 
behaviors by direct modulation of the mesolimbic reward system (Williams and Elmquist, 2012). Indeed, GLP-1producing neurons in the NTS project directly to the VTA and activation of GLP-1Rs in the VTA suppresses feeding behavior by modulating the rewarding value of highly palatable food (Alhadeff et al, 2012; Dickson et al, 2012). Given that the reinforcing effects of drugs of abuse, including cocaine, are regulated by neural circuits that include the VTA (Pierce and Kumaresan, 2006), these findings suggest that GLP-1R signaling in the mesolimbic dopamine system may also influence nonfeeding motivated behaviors such as drug addiction. However, no studies to date have investigated the role of central GLP-1Rs in voluntary cocaine taking.

The present study had four main goals: (1) to determine the role of GLP-1Rs in the VTA in cocaine self-administration; (2) to determine the effects of voluntary cocaine taking on activation of GLP-1-producing neurons in the NTS; (3) to evaluate the potential mechanism(s) underlying cocaineinduced activation of GLP-1-producing neurons in the NTS; and (4) to examine whether endogenous GLP-1R activation in the VTA reduces the reinforcing efficacy of cocaine. Our results indicate that stimulation of GLP-1Rs in the VTA is sufficient to reduce cocaine taking. Consistent with these effects, viral-mediated knockdown of VTA GLP-1R expression was associated with increased cocaine taking on a progressive ratio (PR) schedule of reinforcement, indicating that endogenous GLP-1R signaling in the VTA decreases motivation to self-administer cocaine. Furthermore, we show that systemic cocaine increases activation of NTS GLP-1producing neurons through a putative corticosteronemediated mechanism of action that increases endogenous GLP-1R signaling in the VTA. Taken together, the present findings suggest that central GLP-1Rs may represent a new target for the development of novel medications to treat cocaine addiction.

\section{MATERIALS AND METHODS}

\section{Animals and Housing}

Male Sprague-Dawley rats (Rattus norvegicus) weighing 225$250 \mathrm{~g}$ were obtained from Taconic Laboratories. Animals were individually housed with food and water available ad libitum in their home cage. A $12: 12 \mathrm{~h}$ light/dark cycle was used with the lights on at $0700 \mathrm{~h}$. All experimental procedures were performed during the light cycle. The experimental protocols were consistent with the guidelines issued by the US National Institutes of Health and were approved by the institutional animal care and use committee of the University of Pennsylvania.

\section{Surgery}

Before surgery, rats were anesthetized with $80 \mathrm{mg} / \mathrm{kg}$ ketamine and $12 \mathrm{mg} / \mathrm{kg}$ xylazine (Sigma-Aldrich, St Louis, MO). An indwelling catheter (CamCath, Cambridge, UK) was inserted into the right jugular vein and sutured in place. The catheter was routed to a mesh backmount platform that was implanted subcutaneously dorsal to the shoulder blades. Catheters were flushed following each cocaine selfadministration session with $0.3 \mathrm{ml}$ of antibiotic (Timentin,
$0.93 \mathrm{mg} / \mathrm{ml}$ ) dissolved in heparinized saline and sealed with plastic obturators when not in use.

After catheter insertion, some rats were then immediately mounted in a stereotaxic apparatus (Kopf Instruments, CA) and implanted with cannulae for microinjections. Bilateral guide cannulae (26 gauge; Plastics One, Roanoke, VA) aimed at the VTA were implanted alone or together with a single guide cannula (26 gauge) aimed at the fourth ventricle. Guide cannulae were implanted $2 \mathrm{~mm}$ dorsal to their targeted structures and cemented in place by affixing dental acrylic to stainless steel screws secured in the skull. The coordinates for the ventral ends of the guide cannulae, according to the atlas of Paxinos and Watson (1997), were as follows: VTA (relative to Bregma): $-6.8 \mathrm{~mm} \mathrm{~A} / \mathrm{P}, \pm 0.5 \mathrm{~mm} \mathrm{M} / \mathrm{L}$, and $-6.6 \mathrm{~mm} \mathrm{D} / \mathrm{V}$; fourth ventricle (relative to the occipital suture): $+2.5 \mathrm{~mm} \mathrm{~A} / \mathrm{P}, 0.0 \mathrm{~mm} \mathrm{M} / \mathrm{L}$, and $-5.2 \mathrm{~mm} \mathrm{D} / \mathrm{V}$. An obturator (33 gauge; Plastics One) was inserted into each guide cannula to prevent occlusion.

\section{Cocaine Self-Administration}

Rats were allowed 7 days to recover from surgery before behavioral testing commenced. Rats were initially allowed to lever press for intravenous infusions of cocaine on fixed-ratio 5 (FR5) schedule of reinforcement similar to our previously published methods (Schmidt et al, 2009) (see Supplementary Materials and Methods for more details). Once rats achieved stable responding on the FR5 schedule, as defined by a $<15 \%$ change in the total number of active lever responses on 2 consecutive days, they were switched to a PR schedule of reinforcement. Under the PR schedule, the response requirement for each subsequent infusion increased until the rat failed to meet a requirement in $30 \mathrm{~min}$. The response requirement for the $i$ th reinforcement was given by $R(i)=\left(5 \mathrm{e}^{0.2 \mathrm{i}}-5\right)$. The breakpoint was operationally defined as the last response requirement completed before the termination of the PR test session. PR schedules of reinforcement are commonly used to assess the reinforcing efficacy of drugs and natural rewards (Hodos, 1961). With regard to the present study, lower breakpoints reflect decreased reinforcing efficacy of cocaine (Richardson and Roberts, 1996). Although neither FR nor PR schedules quantify all aspects of drug reinforcement, PR schedules are more appropriate for measuring changes in reinforcer efficacy (Arnold and Roberts, 1997).

Once rats had stabilized their responding for cocaine on the PR schedule ( $~ 5$ days), the effects of intra-VTA administration of the GLP-1R agonist exendin-4 on cocaine selfadministration were evaluated. Using a between-session, within-subjects design, vehicle and exendin-4 (0.005 and $0.05 \mu \mathrm{g})$ were microinjected into the VTA immediately before a PR test session. The effects of corticosterone infusions directly into the fourth ventricle on cocaine selfadministration were tested in separate groups of rats that maintained stable responding on the PR schedule. Using a between-session, within-subjects design, vehicle and hydroxypropyl- $\beta$-cyclodextrin-complexed corticosterone $(0.05$ and $0.5 \mu \mathrm{g})$ were infused directly into the fourth ventricle $15 \mathrm{~min}$ before a PR test session. For all experiments, doses were counterbalanced across test days and each test day was separated by at least one day of self-administration in the absence of a treatment to ensure that responding 
returned to baseline before being tested on the next dose. Potential nonspecific rate-suppressing effects of intra-VTA exendin-4 and intracerebroventricular (ICV) corticosterone were evaluated by assessing the influence of these compounds on sucrose self-administration maintained on the same PR schedule used for the aforementioned cocaine studies (see Supplementary Methods and Materials for more details).

In order to determine whether activation of VTA GLP-1Rs is required for corticosterone-induced attenuation of cocaine taking, the GLP-1R antagonist exendin-(9-39) was microinjected into the VTA before infusions of corticosterone into the fourth ventricle. For this study, a separate cohort of rats was infused with $10 \mu \mathrm{g}$ exendin-(9-39) or vehicle into the VTA and returned to their home cages. Ten minutes later hydroxypropyl- $\beta$-cyclodextrin-complexed corticosterone $(0.5 \mu \mathrm{g})$ or vehicle was infused directly into the fourth ventricle. Rats were then returned to their home cages for 15 min before a PR test session. A between-session, withinsubjects design was used and doses were counterbalanced across PR test sessions.

Corticosterone was administered into the fourth ventricle primarily because microinjections directly into the NTS produce illness-like behaviors in rats. Specifically, intra-NTS infusions of artificial cerebrospinal fluid have been shown to produce conditioned-taste avoidance (Kanoski et al, 2012). Therefore, it is possible that infusions into the NTS could produce generalized avoidance behaviors that would make drawing firm conclusions about our cocaine studies difficult.

\section{Microinjection Procedures}

The obturators were removed from the guide cannulae and 33-gauge stainless steel microinjectors (Plastics One) were inserted. Bilateral infusions into the VTA were performed in a total volume of 100 or $200 \mathrm{nl}$. Infusions into the fourth ventricle were performed in a total volume of $1.0 \mu \mathrm{l}$. Following infusion, microinjectors were left in place for an additional $1 \mathrm{~min}$ in order to allow for diffusion of the drug solution away from the tips of the microinjectors. Using a within-subjects design, each animal served as its own control. To control for potential rank order effects of drug and vehicle administrations, all treatments were counterbalanced across PR test sessions. Cannula placements were verified according to previously described protocols (Hayes et al, 2009; Schmidt et al, 2009) (see Supplementary Materials and Methods for more details).

\section{Viral-Mediated GLP-1 Receptor Knockdown}

To create a short hairpin RNA (shRNA) targeting GLP-1R transcripts, RNA sequences for reduced GLP-1R expression (Origene) were screened in vitro according to previously published methods (Mietlicki-Baase et al, 2015). Briefly, a plasmid designed to express GLP-1Rs (NM_053816; Origene) was transiently transfected alone or in combination with an RNA sequence to reduce GLP-1R expression in a rat immortalized hypothalamic neuronal cell line (R-19; Cedarland Labs). The most robust knockdown of GLP-1Rs was obtained using the following shRNA sequence: 5'-GAT CGGGTTGCTGGTGGAAGGCGTGTATCTGTACTCAAGA GGTACAGATACACGCCTTCCACCAGCAACCTTTTTT-3'.
Our preliminary in vitro studies demonstrated $\sim 88 \%$ knockdown of GLP-1R expression in a rat neuronal cell line transfected with this shRNA (data not shown).

To knock down GLP-1R expression in vivo, this shRNA sequence was cloned and packaged into an adeno-associated virus $(\mathrm{AAV})$ (serotype 1 ; titer $=5.22 \mathrm{e} 12$ ) in collaboration with the Viral Core at the University of Pennsylvania. A GFP-expressing AAV (titer $=5.0 \mathrm{e} 12$ ) was used as a control. To determine the functional significance of endogenous GLP-1R signaling in the VTA, rats were surgically implanted with catheters and VTA-directed guide cannulae as described above. Once rats achieved stable cocaine self-administration on FR5, AAV-expressing GFP (AAV-GFP) or the GLP-1R shRNA (AAV-GLP-1R-shRNA) was infused bilaterally into the VTA (100 nl/hemisphere over $1 \mathrm{~min})$. Microinjectors were left in place for an additional minute after infusion to allow for diffusion away from the injection site. Following an additional 14 days of cocaine self-administration on FR5, motivation to self-administer cocaine was assessed for two consecutive days using a PR schedule. Following cocaine self-administration, brains were dissected and $1 \mathrm{~mm}^{2}$ bilateral micropunches of the VTA were collected to assess GLP-1R expression using quantitative real-time PCR (qPCR). GLP-1R levels were quantified using Taqman gene expression kits (GLP-1R: Rn00562406_m1; GapDH: Rn01775763_g1; Life Technologies) and PCR reagents (Applied Biosystems). qPCR was conducted using an Eppendorf Mastercycler ep realplex2 and the comparative threshold cycle method was used to quantify relative mRNA expression. A VTA-containing coronal section $(30 \mu \mathrm{m})$ was collected from each brain to verify correct placement of AAV injections by visualizing GFP fluorescence (see Figure 6a for a representative placement).

\section{Cocaine Self-Administration and Yoked Saline Controls}

Rats underwent catheterization as described above and were allowed to recover for 7 days before cocaine selfadministration commenced. Rats were randomly assigned to one of two groups: cocaine-experimental or yoked saline controls. Each rat trained to respond for contingent cocaine infusions was paired with a yoked rat that received infusions of saline. Lever pressing for the saline-yoked rats had no scheduled consequences, but these animals received the same number and temporal pattern of infusions as self-administered by the paired cocaine-experimental rat. Cocaine-experimental rats were allowed to lever press for intravenous cocaine infusions on FR1 and FR5 schedules as described above for a total of 21 days.

\section{Plasma Corticosterone}

Immediately after the last self-administration session, one half of the cocaine-experimental and yoked-saline control rats were decapitated. Trunk blood was collected directly into tubes containing heparin and immediately placed on ice. Blood was centrifuged to allow separation of plasma that was collected and frozen at $-80^{\circ} \mathrm{C}$ until assayed using the corticosterone ELISA kit (Enzo Life Sciences, Farmingdale, NY) according to the manufacturer's instructions. Plasma samples were analyzed in duplicate using two ELISA kits. Sample corticosterone concentrations were determined by 
nonlinear regression from the standard curves. The mean coefficient of intraassay variation determined from replicates of randomly chosen samples analyzed in the same assay was $9.6 \%$. The mean coefficient of interassay variation determined from replicates of randomly chosen samples analyzed in different assays was $18.2 \%$.

\section{Immunohistochemistry}

At 90 min following an intraperitoneal injection of cocaine $(10 \mathrm{mg} / \mathrm{kg})$ or saline, rats were deeply anesthetized and transcardially perfused with $0.1 \mathrm{M} \mathrm{PBS}, \mathrm{pH} 7.4$, followed with $4 \%$ formalin in $0.1 \mathrm{M}$ PBS. We chose to administer a bolus dose of cocaine with a 90-min delay before killing to be consistent with previous studies examining c-fos activation in brain nuclei following cocaine exposure and to ensure equivalent and robust plasma cocaine concentrations across all rats (Buffalari and Rinaman, 2014; Zahm et al, 2010). Brains were removed and postfixed in $10 \%$ formalin overnight and then cryoprotected in $20 \%$ sucrose in $0.1 \mathrm{M}$ PBS at $4{ }^{\circ} \mathrm{C}$ for 3 days. Coronal sections $(35 \mu \mathrm{M})$ were cut from the hindbrain using a cryostat (Leica 3050S; Leica, Deerfield, IL). Brain sections were stored in $0.1 \mathrm{M}$ PBS at $4{ }^{\circ} \mathrm{C}$ until processed. Immunofluorescence in the NTS was quantified in each brain ( $n=4 /$ treatment) using four representative coronal sections taken at the level of the obex. Double immunostaining for the GLP-1 precursor peptide preproglucagon (GLP-1) and c-fos was performed on freefloating coronal sections containing the NTS according to modified procedures from our previously published studies (Alhadeff et al, 2012; Holland et al, 2014) (see Supplementary Materials and Methods for more details).

To investigate whether increased plasma corticosterone levels are associated with activation of GLP-1-producing neurons in the NTS, corticosterone was administered to drug-naive rats. At $30 \mathrm{~min}$ after rats received an acute injection of corticosterone $(15 \mathrm{mg} / \mathrm{kg}$, s.c.) or vehicle, animals were perfused and brains were removed and postfixed in $10 \%$ formalin overnight as described above. Double immunohistochemistry was performed as described in the Supplementary Materials and Methods. Immunofluorescence in the NTS was quantified in each brain $(n=3$ / treatment) using four representative coronal sections taken at the level of the obex. The dose of corticosterone was based on a previous study that examined the effects of peripheral corticosterone on central GLP-1 expression (Zhang et al, 2009).

\section{Drugs}

Cocaine was obtained from the National Institute on Drug Abuse (Rockville, MD) and dissolved in bacteriostatic $0.9 \%$ saline. Exendin-4 and exendin-(9-39) were purchased from the American Peptide Company (Sunnyvale, CA) and were dissolved in artificial cerebrospinal fluid (aCSF; Harvard Apparatus, Holliston, MA). Hydroxypropyl- $\beta$-cyclodextrincomplexed corticosterone was purchased from SigmaAldrich and dissolved in sterile $0.9 \%$ saline. The dose ranges and time course of administration for each of the aforementioned pharmacological compounds were based on the following intracranial microinjection experiments in rats: exendin-4 (Alhadeff et al, 2012; Mietlicki-Baase et al, 2013), exendin-(9-39) (Alhadeff et al, 2012), and hydroxypropyl- $\beta$ cyclodextrin-complexed corticosterone (Graf et al, 2013).

\section{Statistics}

For the cocaine self-administration experiments utilizing exendin-4 in the VTA or corticosterone in the fourth ventricle, the total mean active lever responses, inactive lever responses, infusions, and breakpoints were analyzed with one-way repeated measures ANOVAs. Total mean active lever responses, inactive lever responses, infusions, and breakpoints for the VTA exendin-(9-39)+fourth ventricle corticosterone experiments were analyzed with two-way repeated measures mixed-factors ANOVAs. Pairwise comparisons were made with Tukey's HSD $(p<0.05)$ following all one-way ANOVAs and Bonferroni correction following two-way ANOVAs $(p<0.05)$. Total mean active lever responses, inactive lever responses, pellets, and breakpoints for all sucrose self-administration test sessions were analyzed with paired $t$-tests. Plasma corticosterone levels and total mean active lever responding in the cocaine-experimental and yoked-saline control rats as well as PR data in the AAV studies were analyzed with unpaired $t$-tests.

\section{RESULTS}

\section{Intra-VTA Administration of the GLP-1R Agonist Exendin-4 Attenuates Cocaine Self-Administration at a Dose Subthreshold for Effects on Sucrose Self-Administration in Rats}

Total active lever responses, breakpoints, and total number of cocaine infusions (mean \pm SEM) in animals pretreated with exendin- 4 (vehicle and 0.005 or $0.05 \mu \mathrm{g}, n=7 /$ treatment) in the VTA and responding for cocaine $(0.75 \mathrm{mg} / \mathrm{kg})$ are shown in Figure $1 \mathrm{a}-\mathrm{c}$, respectively. These data were analyzed with separate one-way ANOVAs that revealed significant main effects of treatment on total active lever responding $(\mathrm{F}(2,20)=$ 10.29, $p<0.01)$, breakpoints $(\mathrm{F}(2,20)=10.68, p<0.01)$, and infusions $(\mathrm{F}(2,20)=11.49, \quad p<0.01)$. Subsequent pairwise analyses showed that total active lever responses, breakpoints, and total infusions were significantly different between rats pretreated with vehicle and those pretreated with $0.05 \mu \mathrm{g}$ exendin-4 (Tukey's HSD, $p<0.05$ ). No significant differences were found on inactive lever responding between treatments $(\mathrm{F}(2,20)=1.0, p=0.40$; data not shown).

To generate a cocaine dose-response curve, a separate cohort of rats $(n=11)$ was allowed to self-administer lower $(0.19 \mathrm{mg} / \mathrm{kg})$ and higher $(1.5 \mathrm{mg} / \mathrm{kg})$ unit doses of cocaine than the dose used in Figure $1(0.75 \mathrm{mg} / \mathrm{kg})$. Total active lever responses, breakpoints, and total number of cocaine infusions (mean \pm SEM) in animals pretreated with exendin-4 (vehicle or $0.05 \mu \mathrm{g}$ ) in the VTA are shown in Supplementary Figure S1A-C, respectively. These data were analyzed with separate two-way repeated measures ANOVAs that revealed significant treatment $\times$ unit cocaine dose interactions for total active lever responding $(\mathrm{F}(1,10)=25.99, p<0.001)$, breakpoints $(\mathrm{F}(1,10)=9.673, p<0.05)$, and infusions $(\mathrm{F}(1,10)=4.856$, $p<0.05)$. Subsequent pairwise analyses showed that total active lever responses, breakpoints, and total infusions were significantly different between rats pretreated with vehicle and those pretreated with $0.05 \mu \mathrm{g}$ exendin- 4 for each dose of 

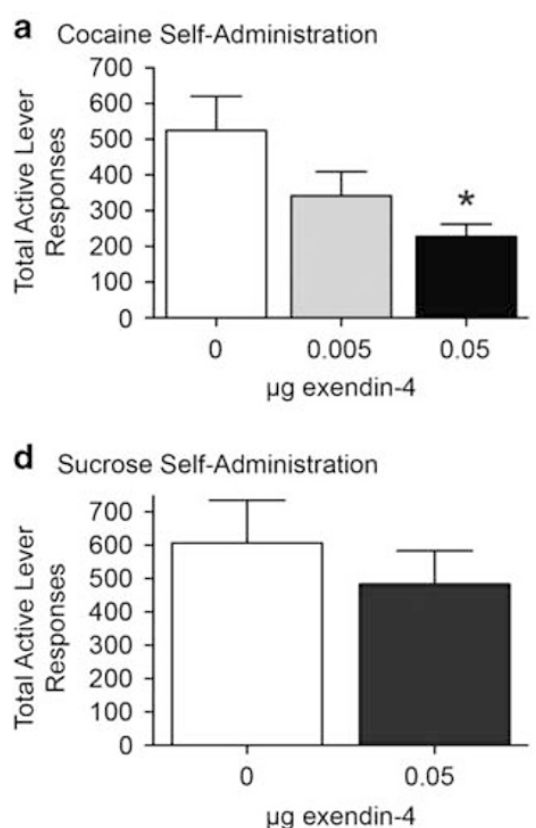
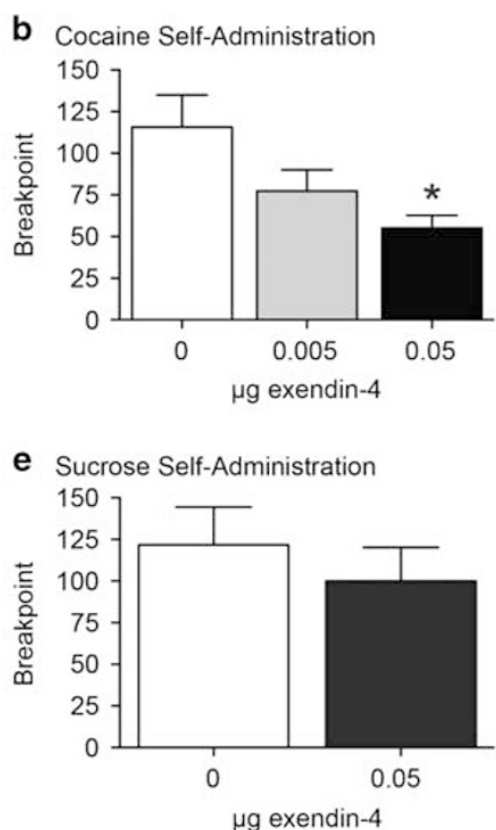

C Cocaine Self-Administration

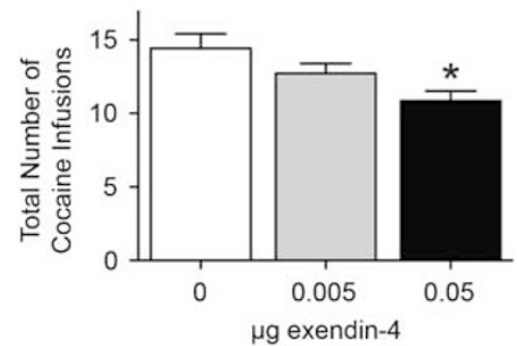

f Sucrose Self-Administration

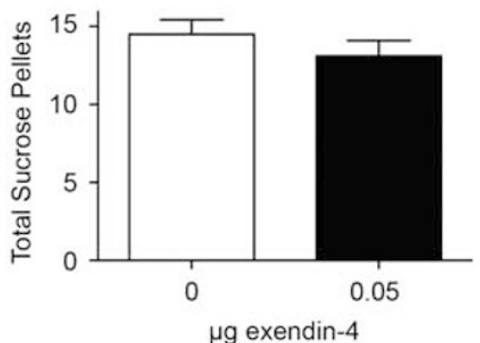

Figure I Administration of the GLP-I receptor agonist exendin-4 into the VTA dose-dependently attenuates cocaine self-administration maintained on a

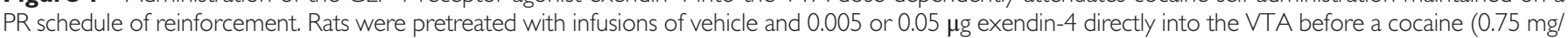

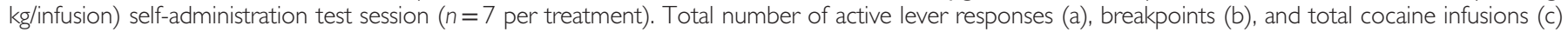

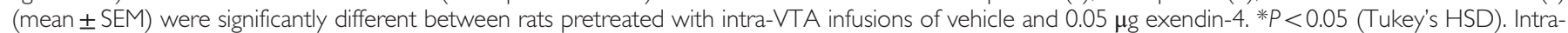

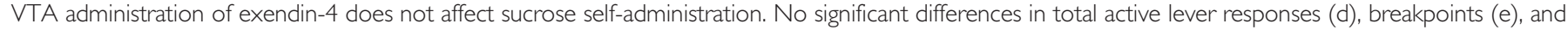

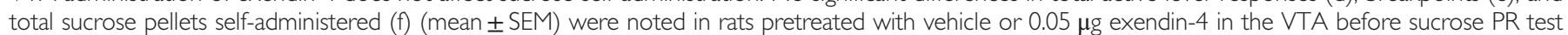
sessions ( $n=10$ per treatment; $p>0.05$, paired $t$-test).

self-administered cocaine (Tukey's HSD, $p<0.05$ ). No significant differences were found on inactive lever responding between treatments $(F(1,10)=0.31, p=0.59$; data not shown).

Although intra-VTA administration of exendin- 4 had no significant effect on inactive lever responding, one could argue that responses were uniformly too low to meaningfully assess potential rate-suppressant effects of drug treatment. Therefore, we also assessed the ability of intra-VTA microinjections of exendin-4 to alter sucrose self-administration. Total active lever responses, breakpoints, and total sucrose pellets are shown in Figure $1 \mathrm{~d}-\mathrm{f}$, respectively, for rats $(n=10)$ pretreated with vehicle or $0.05 \mu \mathrm{g}$ exendin- 4 directly into the VTA before sucrose self-administration sessions. There were no significant differences in total active lever responding $(t(9)=1.24$, $p=0.25)$, breakpoints $(t(9)=1.16, p=0.28)$, or total pellets self-administered $(t(9)=1.37, p=0.21)$ between treatments. Taken together with the cocaine self-administration studies above, these data indicate that attenuation of cocaine taking following administration of $0.05 \mu \mathrm{g}$ exendin- 4 into the VTA is not because of drug-induced motor impairments and that this behaviorally relevant dose of exendin-4 does not alter sucrosetaking behavior. These findings are consistent with a previous study demonstrating that intra-VTA infusions of a similar dose of exendin-4 $(0.03 \mu \mathrm{g})$ does not alter locomotor activity or $2 \mathrm{~h}$ sucrose intake (Dickson et al, 2012).

\section{Cocaine Self-Administration Increases Plasma Corticosterone Levels}

In order to replicate previously published studies demonstrating elevated plasma corticosterone levels in rats self-administering cocaine (Galici et al, 2000; Goeders and Guerin, 1996; Mantsch et al, 2000), we allowed rats to selfadminister cocaine and each cocaine-experimental rat was paired with a yoked-saline control that received the same number and temporal pattern of infusions ( $n=14 /$ treatment). Total active lever responses (mean \pm SEM) for the last day of cocaine self-administration are shown in Figure 2a. There was a significant difference in active lever responding between cocaine-experimental and yoked-saline control rats $(t(26)=$ $10.41, p<0.001$ ). Plasma corticosterone levels (Figure $2 b$ ) were significantly greater in cocaine-experimental rats compared with yoked-saline control rats $(t(26)=2.65, p<0.01)$. These findings clearly indicate that cocaine taking is associated with elevated plasma corticosterone levels.

\section{Peripheral Corticosterone Administration Increases Activation of GLP-1-Producing Neurons in the NTS}

GLP-1 is the primary posttranslational product of the preproglucagon (PPG) gene and central GLP-1 is produced almost exclusively in the NTS of the caudal brainstem (Han et al, 1986; Larsen et al, 1997). There is some evidence that corticosterone administration dynamically alters PPG transcription in the NTS and increases central GLP-1 release in rats (Zhang et al, 2009). Therefore, we hypothesized that peripheral corticosterone administration would increase activation of GLP-1-producing PPG neurons in the NTS. Activation of NTS GLP-1-producing neurons, as measured by double immunohistochemistry to label c-fos and PPG (precursor to GLP-1) at the level of the obex, was increased in rats treated with corticosterone $(15 \mathrm{mg} / \mathrm{kg}$, s.c.) when 
a

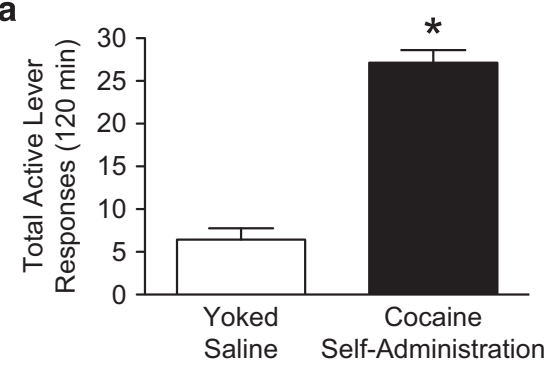

c

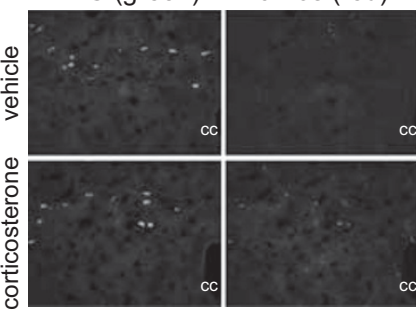

e

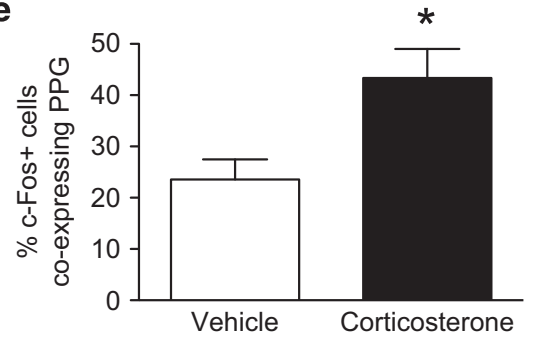

b

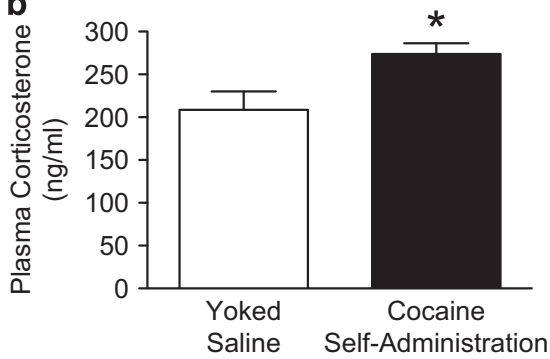

d

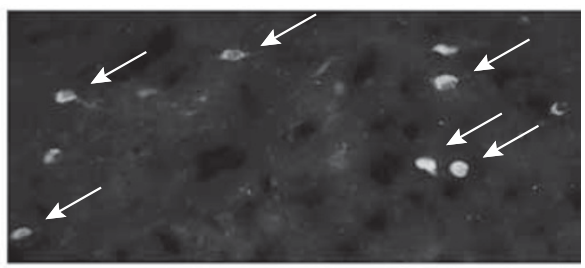

f

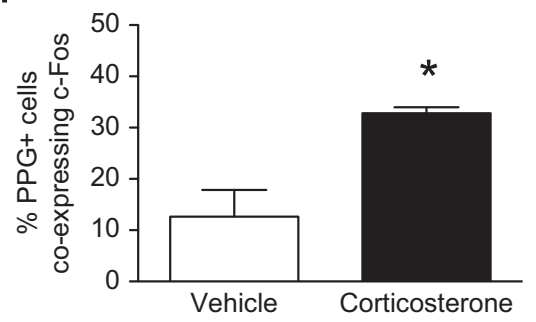

Figure 2 Cocaine self-administration is associated with increased plasma corticosterone levels and peripheral corticosterone administration increases activation of PPG-expressing neurons in the NTS. (a) Total active lever responses (mean \pm SEM) are shown for cocaine-experienced rats and yoked-saline controls. (b) Plasma corticosterone levels were significantly different in cocaine-experienced rats when compared with yoked-saline controls ( $n=14$ per treatment). $* P<0.01$ for total active lever responses and plasma corticosterone levels between treatments (unpaired $t$-test). (c) Representative immunofluorescent micrographs $(\times 10)$ showing activation of NTS GLP-I-producing neurons, as measured using double immunohistochemistry for PPG (green) and c-fos (red), was increased in rats treated with corticosterone $(15 \mathrm{mg} / \mathrm{kg}$, s.c.) vs vehicle. (d) High-magnification image $(\times 20)$ of the insert in $(\mathrm{c})$ showing neuron colocalization of PPG and c-fos immunoreactivity in the NTS of a corticosterone-treated rat. Total percentages of c-Fos-positive (+) cells coexpressing PPG (e) and PPG-positive (+) cells coexpressing c-Fos (f) were significantly increased in the NTS of rats treated with corticosterone $(n=4)$ compared with vehicle-treated controls $(n=3)$; cc, central canal. A full color version of this figure is available at the Neuropsychopharmacology journal online.

compared with vehicle-treated controls (Figure 2c). A representative image of colocalization of $c$-fos and PPG immunoreactivity in the caudal NTS of a corticosteronetreated rat is shown in Figure 2d. Total percentages of c-Fospositive cells coexpressing PPG $(t(5)=2.64, p<0.05)$ and PPG-positive cells coexpressing c-Fos $(t(5)=4.40, p<0.01)$ were significantly increased in the NTS of rats treated with corticosterone compared with vehicle-treated controls (Figure $2 \mathrm{e}$ and f, respectively). Approximately $33 \%$ of GLP-1-producing neurons in the NTS were activated in rats treated with corticosterone. Importantly, there were no differences in total PPG-expressing cells between treatments (data not shown). These data support the hypothesis that cocaine-induced increases in plasma corticosterone levels activate GLP-1-producing PPG neurons in the NTS.

\section{Cocaine Increases Activation of NTS GLP-1-Producing Neurons}

Rats receiving a systemic injection of cocaine or saline were used to determine whether cocaine can increase activation of GLP-1-producing neurons in the NTS, as measured by expression of c-fos in GLP-1-immuno-positive neurons. Representative images of cells in the NTS double labeled for GLP-1 and c-fos are shown in Figure 3a. Although the total number of GLP-1-positive cells did not differ between treatments (Figure $3 b ; t(6)=0.76, p<0.48$ ), there was a significant difference in total $c$-fos-positive cells between cocaine-experimental rats and yoked-saline controls as expected (Figure $3 c ; t(6)=56.73, p<0.0001$ ). Quantification of colabeling in NTS neurons revealed that $70.4 \pm 1.42 \%$ of GLP-1-expressing neurons in the NTS are c-fos positive and $26.3 \pm 0.93 \%$ of c-fos-expressing neurons in the NTS are GLP-1 positive in cocaine-experimental rats (Figure 3d). These results clearly indicate that systemic cocaine increases activation of NTS GLP-1-expressing neurons and suggest that cocaine-induced increases in corticosterone signaling in the caudal brainstem may represent a compensatory mechanism to reduce cocaine consumption by activating the central GLP-1 system that sends direct monosynaptic projections to the VTA (Alhadeff et al, 2012). 

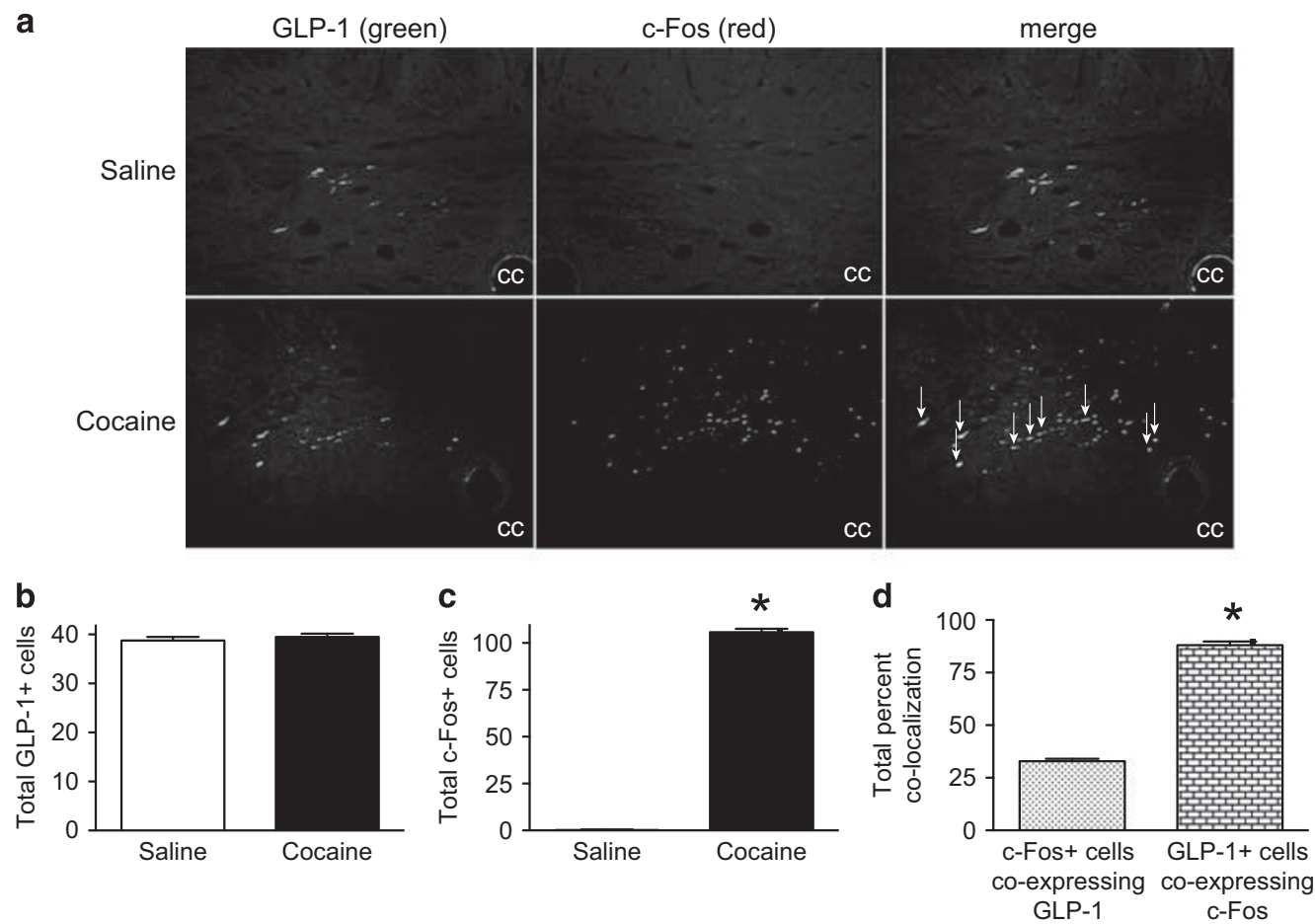

Figure 3 Cocaine administration is associated with increased activation of GLP-I-expressing neurons in the NTS. (a) Representative images of cells in the NTS double labeled for GLP-I (green) and c-Fos (red) are shown for rats receiving systemic $10 \mathrm{mg} / \mathrm{kg}$ cocaine or saline. Although total NTS GLP-I-positive cells (b) were not different between cocaine-treated rats and saline controls, there was significant increase in total c-Fos-positive cells (c) in the NTS of rats receiving cocaine compared with saline controls. (d) Quantification of colabeling in NTS neurons revealed that 70.4 \pm I.42\% of GLP- I-expressing neurons in the NTS are c-Fos positive in cocaine-treated rats $(n=4 /$ treatment); $c c$, central canal. $* P<0.05$. A full color version of this figure is available at the Neuropsychopharmacology journal online.

\section{Administration of Corticosterone Directly into the Fourth Ventricle Attenuates Cocaine, But Not Sucrose, Self-Administration in Rats}

In order to determine whether increased corticosterone signaling in the caudal brainstem regulates cocaine taking, corticosterone was administered directly into the fourth ventricle. ICV infusions were chosen primarily because microinfusions directly into the NTS produce aversive-like behaviors in rats (Kanoski et al, 2012). Total active lever responses, breakpoints, and total cocaine infusions (mean \pm SEM) for animals pretreated with corticosterone (vehicle and 0.05 or $0.5 \mu \mathrm{g}, n=7 /$ treatment) into the fourth ventricle before a cocaine self-administration test session are shown in Figure $4 a-c$, respectively. There were significant main effects of treatment on active lever responses $(\mathrm{F}(2,20)=$ $4.00, p<0.05)$, breakpoints $(\mathrm{F}(2,20)=4.62, p<0.05)$, and total number of cocaine infusions $(\mathrm{F}(2,20)=4.14, p<0.05)$. Subsequent pairwise analyses showed a significant difference between animals pretreated with $0.5 \mu \mathrm{g}$ corticosterone and vehicle (Tukey's HSD, $p<0.05$ ). No significant differences in responses made on the inactive lever were found between treatments $(\mathrm{F}(2,20)=0.04, p<0.96$; data not shown $)$.

Total active lever responses, breakpoints, and total sucrose pellets self-administered are shown in Figure $4 d-f$, respectively, for rats $(n=10)$ treated with vehicle or $0.5 \mu \mathrm{g}$ corticosterone directly into the fourth ventricle before sucrose self-administration test sessions. There were no significant differences in total active lever responding $(t(9)=$ $0.31, p<0.77)$, breakpoints $(t(9)=0.23, p<0.82)$, and total sucrose pellets self-administered $(t(9)=0.97, \quad p<0.36)$ between treatments. Taken together, these data indicate that attenuation of cocaine taking following administration of $0.5 \mu \mathrm{g}$ corticosterone directly into the fourth ventricle is reinforce specific and not due to general motor suppressant effects of drug treatment.

\section{Intra-VTA Administration of the GLP-1R Antagonist Exendin-(9-39) Blocks the Suppressive Effects of Fourth ICV Corticosterone Administration on Cocaine Taking}

NTS GLP-1-expressing neurons send direct monosynaptic projections to the VTA (Alhadeff et al, 2012). To determine whether fourth ICV corticosterone-induced attenuation of cocaine taking is mediated by increased endogenous GLP-1R signaling in the VTA, a separate cohort of rats was pretreated with the GLP-1R antagonist exendin-(9-39) before corticosterone infusions into the fourth ventricle. Total active lever responses, breakpoints, and total cocaine infusions (mean \pm SEM) following corticosterone administration into the fourth ventricle are shown in Figure $5 \mathrm{a}-\mathrm{c}$, respectively $(n=13 /$ treatment). There were significant brain region $\times$ treatment interactions for active lever responding $(\mathrm{F}(1,24)=5.01, \quad p<0.05), \quad$ breakpoints $\quad(\mathrm{F}(1,24)=5.91$, $p<0.05)$, and total cocaine infusions $(\mathrm{F}(1,24)=6.37$, $p<0.05)$. The post hoc analyses showed significant differences between vehicle $+0.5 \mu \mathrm{g}$ corticosterone and all other treatments. No significant differences on inactive lever responding were found between brain regions and treatments $(\mathrm{F}(1,24)=0.54, p=0.47$; data not shown). 


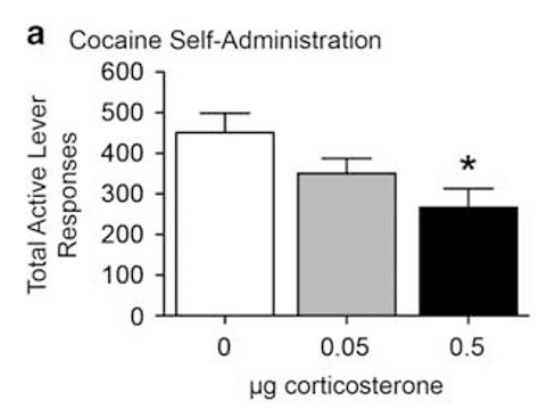

d Sucrose Self-Administration

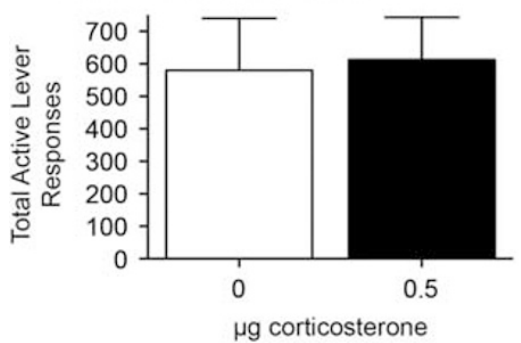

b Cocaine Self-Administration

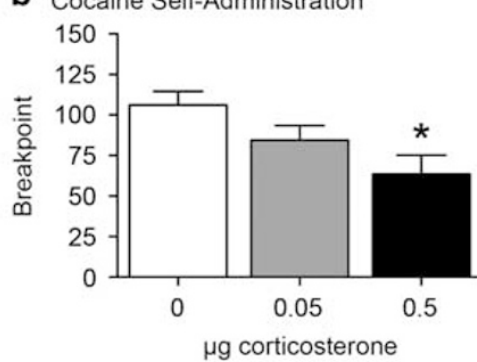

e Sucrose Self-Administration

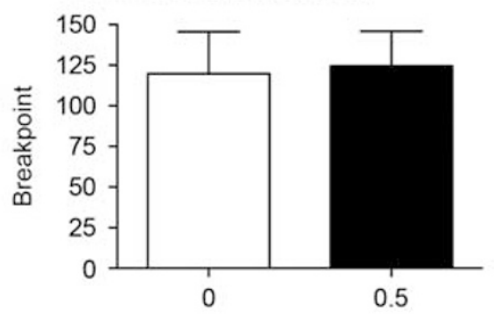

$\mu \mathrm{g}$ corticosterone

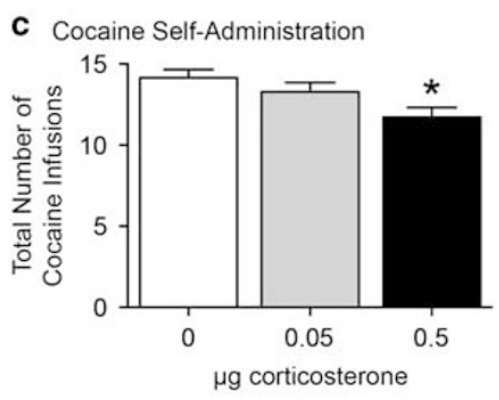

f Sucrose Self-Administration

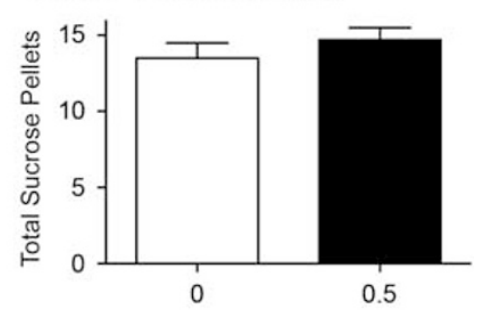

$\mu \mathrm{g}$ corticosterone

Figure 4 Administration of corticosterone directly into the fourth ventricle dose-dependently attenuated cocaine self-administration. Total number of active lever responses (a), breakpoints (b), and total cocaine infusions (c) (mean \pm SEM) following microinjections of vehicle and 0.05 and $0.5 \mu \mathrm{g}$ corticosterone into the fourth ventricle of rats self-administering cocaine on a PR schedule of reinforcement $(n=7$ per treatment). *P<0.05 for active lever responding and breakpoints between vehicle and $0.5 \mu \mathrm{g}$ corticosterone (Tukey's HSD). Infusions of corticosterone directly into the fourth ventricle had no effect on sucrose self-administration. Total active lever responses (d), breakpoints (e), and total sucrose pellets ( $f$ ) (mean \pm SEM) in rats ( $n=10$ per treatment) self-administering sucrose pellets on a PR schedule of reinforcement. There were no significant differences between treatments ( $p>0.05$, paired $t$-test).
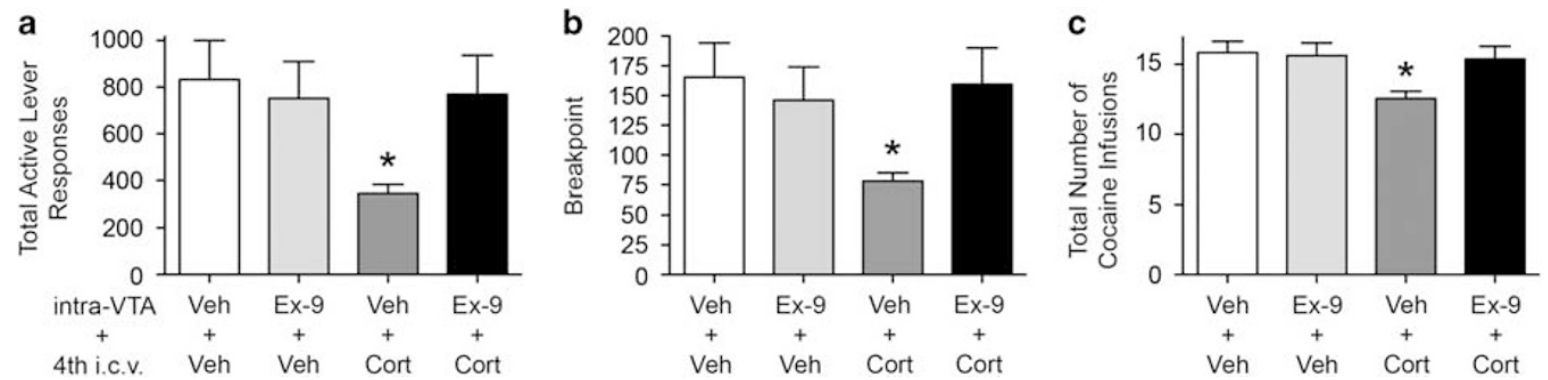

Figure 5 Corticosterone-mediated attenuation of cocaine self-administration is prevented in rats pretreated with infusions of the GLP-I receptor antagonist exendin-(9-39) into the VTA. Intra-VTA infusions of $10.0 \mu \mathrm{g}$ exendin-(9-39) prevented intracerebroventricular $0.5 \mu \mathrm{g}$ corticosterone-mediated reductions in total active lever responses (a), breakpoints (b), and total cocaine infusions (c). There were significant differences in active lever responding and breakpoints between vehicle+corticosterone and all other treatments $(* p<0.05$, Bonferroni correction, $n=13$ per treatment).

Microinjection sites targeting the VTA for all behavioral pharmacology experiments are shown in Supplementary Figure S2. Taken together, these results strongly suggest that the intake suppressive effects of corticosterone in the caudal brainstem are due, in part, to increased GLP-1R activation in the VTA.

\section{Decreased Expression of VTA GLP-1Rs Augments Cocaine Taking}

To determine whether endogenous GLP-1R signaling in the VTA reduces motivation to self-administer cocaine, AAVGFP and AAV-GLP-1R-shRNA were administered directly into the VTA of rats responding for cocaine on an FR5 schedule of reinforcement. At 14 days after infection, viral- mediated expression of GFP in the VTA was maximal (Figure 6a) and GLP-1R transcript expression was significantly reduced $(\sim 47 \%)$ in rats infected with AAV-GLP-1RshRNA when compared with controls (Figure $6 \mathrm{~b},(t(5)=$ $2.56, p<0.05)$. Total cocaine infusions did not differ between treatments $(t(16)=0.16, p<0.88)$ during the FR5 phase (data not shown). However, trends toward increased breakpoints $(t(16)=1.41, p<0.17)$ and total cocaine infusions $(t(16)=$ $1.50, p<0.15)$ were observed during the first PR test in rats treated with AAV-GLP-1R-shRNA as compared with controls (Figure $6 \mathrm{c}$ and d). During a subsequent PR test $24 \mathrm{~h}$ later, breakpoints $(t(16)=2.16, p<0.05)$ and total cocaine infusions $(t(16)=2.20, p<0.05)$ were significantly increased in rats infused with intra-VTA AAV-GLP-1R-shRNA compared with AAV-GFP controls (Figure 6e and f). No 
a
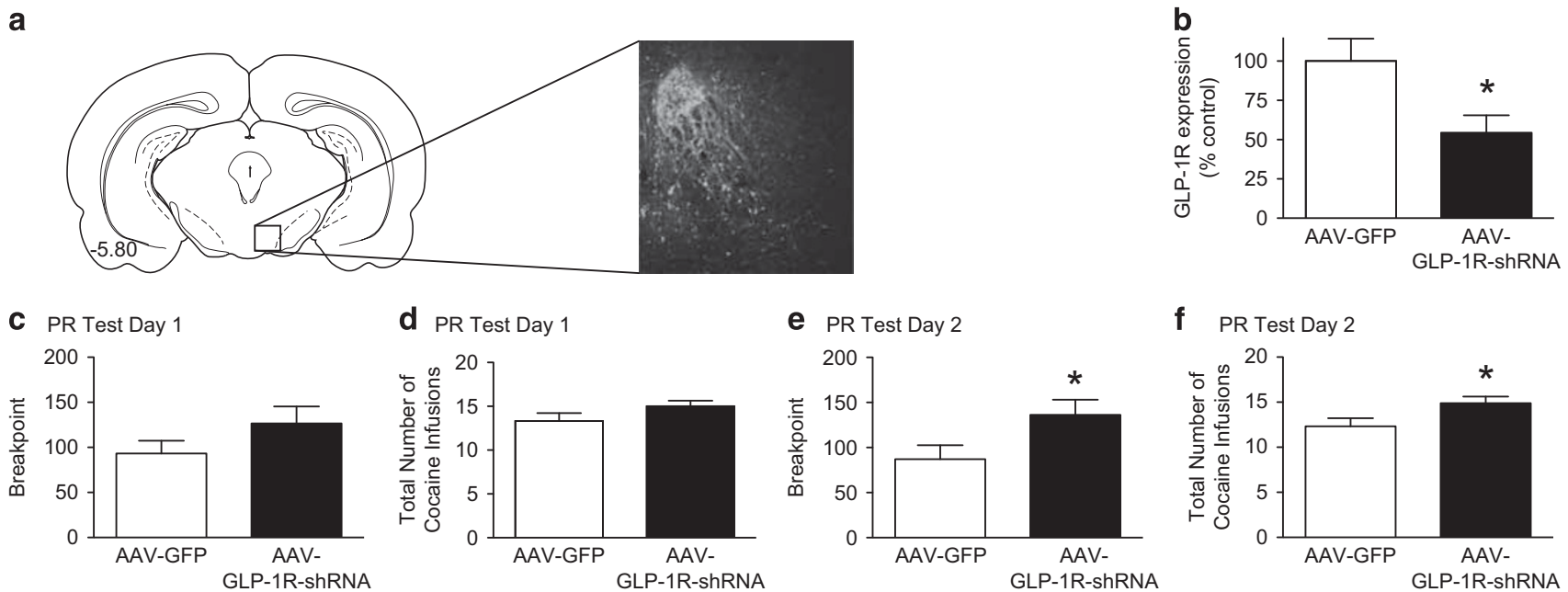

f PR Test Day 2

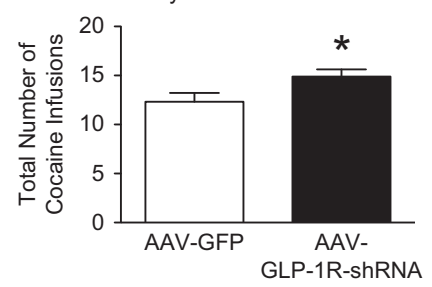

Figure 6 Decreased GLP-I receptor expression in the VTA is sufficient to augment cocaine self-administration on a PR schedule of reinforcement. (a) Coronal section depicting VTA-targeted infusions AAV-GFP $(n=10)$ and AAV-GLP-IR-shRNA $(n=9)$. The insert shows GFP-expressing cells in the VTA 14 days after infection in a representative micrograph. (b) Endogenous GLP-I receptor expression was significantly reduced ( $\sim 7 \%$ ) in the VTA of rats treated with AAV-GLP-IR-shRNA compared with controls I 4 days after infection. Nonsignificant trends toward increased breakpoints $(c)(p<0.17)$ and total cocaine infusions $(d)(p<0.15)$ were observed in rats infused with AAV-GLP-IR-shRNA when compared with controls during the first PR test session. Statistically significant increases in breakpoints (e) and total cocaine infusions ( $f$ ) were observed between treatments during the second PR test session (* $p<0.05$, unpaired t-tests).

significant changes in inactive lever responding were found between treatments on PR test day $1(t(16)=0.80, p<0.44)$ and PR test day $2(t(16)=1.18, p<0.26)$. These data suggest that increased endogenous GLP-1R activation in the VTA is a homeostatic response to drug taking that functions to reduce motivation to self-administer cocaine.

\section{DISCUSSION}

The current study is the first to our knowledge demonstrating a critical role for central GLP-1Rs in voluntary cocainetaking behavior. Specifically, administration of the GLP-1R agonist exendin-4 directly into the VTA attenuated cocaine self-administration in rats. The behaviorally relevant dose of exendin-4 that reduced cocaine taking did not affect sucrose self-administration, indicating that the suppressive effects of this dose of intra-VTA exendin-4 on cocaine self-administration are reinforce specific and not due to nonspecific effects (eg, general motor impairments). The present results also demonstrate that cocaine taking is associated with increased plasma corticosterone levels and that systemic administration of cocaine activates GLP-1-producing neurons in the NTS. Moreover, peripheral administration of corticosterone increased activation of NTS GLP-1-producing neurons. Taken together, these findings suggest that cocaine taking may activate NTS GLP-1producing neurons that project to the VTA through a corticosterone-mediated mechanism of action. Consistent with this hypothesis, infusions of corticosterone directly into the fourth ventricle attenuated cocaine self-administration. The suppressive effects of intraventricular corticosterone on cocaine taking were blocked in rats pretreated with intraVTA infusions of the GLP-1R antagonist exendin-(9-39), indicating that hindbrain corticosterone reduces cocaine taking, in part, through activation of the endogenous central
GLP-1 system. These data support the hypothesis that voluntary cocaine taking activates GLP-1-producing neurons in the NTS through a corticosterone-mediated mechanism of action and that increased GLP-1R signaling in forebrain areas, including the VTA, represents a negative-feedback response that reduces the reinforcing efficacy of cocaine. Consistent with this notion, reduced expression of endogenous GLP-1Rs in the VTA augmented cocaine selfadministration.

\section{GLP-1 Receptors and Drug Addiction}

Emerging evidence indicates that GLP-1Rs may play an important role in drug addiction and that systemic administration of GLP-1R agonists reduces the rewarding effects of drugs of abuse (Engel and Jerlhag, 2014; Skibicka, 2013). Recent studies show that peripheral administration of a GLP-1R agonist attenuates psychostimulant-induced conditioned place preference (CPP) and that these effects are associated with reduced extracellular dopamine levels in the nucleus accumbens of mice (Egecioglu et al, 2013b; Graham et al, 2013). Consistent with these studies, peripheral exendin-4 administration reduces nicotine-induced CPP and nicotine-induced increases in extracellular accumbens dopamine levels in mice (Egecioglu et al, 2013a). Moreover, peripheral administration of exendin-4 or GLP-1 decreases alcohol consumption in both mice and rats (Egecioglu et al, 2013c; Shirazi et al, 2013). These findings are certainly provocative and suggest a role for GLP-1Rs in drug addiction. However, drawing firm conclusions based on these studies is difficult primarily because of the exceedingly high doses of exendin-4 tested. Nausea and malaise-like symptoms are common adverse effects associated with high doses of peripherally administered GLP-1R agonists in both humans and rodents (Buse et al, 2009; Kanoski et al, 2012). It is possible and likely that the very high doses of exendin-4 
used in the aforementioned CPP studies are producing malaise-like effects. Indeed, decreased inactive lever responding, a measure of general motor suppressant effects of a drug treatment, was observed following peripheral exendin-4 pretreatment in rats self-administering alcohol (Egecioglu et al, 2013c). Collectively, these limitations make it difficult to determine whether the effects of peripheral exendin-4 administration on drug reward are specific to drug reinforcement or are due to adverse malaise-like effects.

The present results contribute to and expand upon the aforementioned studies demonstrating a role for GLP-1Rs in drug addiction. Here, we show for the first time that stimulation of central GLP-1Rs is sufficient to attenuate voluntary cocaine-taking behavior in rats. These results are consistent with a recent study demonstrating that activation of GLP-1Rs in the VTA attenuates alcohol consumption in rats (Shirazi et al, 2013). Thus, VTA GLP-1Rs mediate the reinforcing effects of both psychostimulants and alcohol.

Importantly, the behaviorally relevant dose of exendin-4 used in our study does not alter normal chow intake or promote pica, a rodent model of nausea, when injected into the VTA of rats (Alhadeff et al, 2012; Dickson et al, 2012). Moreover, intra-VTA administration of exendin-4 did not affect sucrose self-administration in our study. Therefore, it is unlikely that the intake suppressive effects of intra-VTA exendin- 4 on cocaine taking were due to malaise-like symptoms. Interestingly, our study identifies a dose of exendin-4 $(0.05 \mu \mathrm{g})$ that selectively attenuates cocaine, but not sucrose, taking when infused into the VTA. In contrast, a previous study found that intra-VTA infusions of $0.03 \mu \mathrm{g}$ exendin-4 decreased sucrose self-administration only transiently in the first $60 \mathrm{~min}$ of a $120 \mathrm{~min}$ operant session (Dickson et al, 2012). In the present study, PR test sessions had durations of 90-120 min. Our data, therefore, are consistent with the findings of Dickson et al (2012) and indicate that doses of exendin-4 lower than those required to decrease sucrose self-administration may selectively attenuate cocaine taking when infused into the VTA. Taken together, these findings indicate that increased activation of GLP-1Rs in the VTA attenuates both cocaine and sucrose reinforcement and suggest that targeting VTA GLP-1R signaling may be an effective strategy to treat obesity and cocaine addiction.

The neurobiological mechanisms underlying the suppressive effects of intra-VTA exendin-4 on cocaine taking are not clear. Peripheral administration of exendin- 4 is associated with decreased extracellular dopamine levels in the nucleus accumbens of mice receiving an injection of cocaine (Egecioglu et al, 2013b). These results suggest that intraVTA exendin-4 infusions may attenuate cocaine taking, in part, by reducing accumbens dopamine release. Recent evidence also indicates that activation of VTA GLP-1 receptors modulates glutamate signaling in the VTA of drug-naive rats (Mietlicki-Baase et al, 2013). Future studies are therefore required to elucidate the neurochemical mechanisms underlying the effects of VTA GLP-1 receptor activation on cocaine taking.

\section{NTS and Cocaine Addiction}

Previous studies indicate that acute cocaine exposure increases c-fos expression, a measure of neuronal activity, in the NTS (Grabus et al, 2004; Zahm et al, 2010). The NTS is a heterogeneous brain structure comprising distinct and segregated cell populations, including noradrenergic and peptidergic neurons, that integrate and modulate autonomic function, energy balance, and motivated feeding behaviors (Grill and Hayes, 2012; Rinaman, 2010). Emerging evidence suggests that NTS noradrenergic neurons are activated by acute cocaine and may play an important role in cocaine seeking (Buffalari and Rinaman, 2014). The present study expands upon these findings and demonstrates that systemic administration of cocaine increases c-fos expression in the NTS, with the most pronounced effects in the caudal NTS. The ability of cocaine to preferentially activate more caudal regions of the NTS is consistent with feeding studies showing that intake of highly palatable food, but not normal chow, is regulated by GLP-1 afferent projections from the caudal NTS to the VTA (Alhadeff et al, 2012; Dickson et al, 2012). Our data also indicate that, in addition to GLP-1-positive cells, cocaine also increases activation of other distinct cell populations in the NTS. Approximately 75\% of c-fos-positive cells in the NTS did not coexpress GLP-1 in cocaine-treated rats. The phenotype of these cells remains to be identified. However, it is possible that cocaine also activates noradrenergic cells in the NTS (Buffalari and Rinaman, 2014). These data suggest that increased activation of NTS GLP-1producing neurons may represent an endogenous negativefeedback response to cocaine taking that functions to reduce the reinforcing efficacy of cocaine. This hypothesis is supported by our finding that reduced endogenous GLP-1R expression in the VTA augments cocaine taking.

\section{Mechanisms Underlying Cocaine-Induced Activation of GLP-1-Expressing Neurons in the NTS}

GLP-1 is the primary posttranslational product of the PPG gene that is expressed in the brain almost exclusively in the NTS (Han et al, 1986; Larsen et al, 1997). Transcription of PPG in the NTS is increased following corticosterone administration in drug-naive rats (Zhang et al, 2009). Consistent with this study, we show that peripheral corticosterone administration increases activation of PPG-expressing/GLP-1-producing neurons in the NTS. Moreover, cocaine self-administration was associated with increased plasma corticosterone levels, suggesting that cocaine taking may increase activation of GLP-1-producing neurons in the NTS through a corticosterone-mediated mechanism of action. This hypothesis is supported by our studies showing that administration of corticosterone directly into the fourth ventricle attenuated cocaine self-administration and that these effects were blocked in animals pretreated with intraVTA infusions of a GLP-1R antagonist. These findings indicate that cocaine-induced elevations in plasma corticosterone activate GLP-1-producing neurons in the caudal NTS and increase endogenous GLP-1 signaling in the VTA to reduce cocaine taking. In addition to the VTA, NTS GLP-1producing neurons target distinct forebrain regions implicated in cocaine taking and seeking including the nucleus accumbens, amygdala, lateral septum, lateral hypothalamus, and tegmental nuclei ( $\mathrm{Gu}$ et al, 2013; Merchenthaler et al, 1999; Schmidt et al, 2005, 2009). Therefore, it is possible that endogenous GLP-1R signaling in these nuclei also plays a role in the suppressive effects of hindbrain corticosterone on 
cocaine taking. A recent study showed that constitutive knockdown of GLP-1Rs augments cocaine-induced CPP, effects that are reversed when GLP-1Rs are reexpressed in the lateral septum (Harasta et al, 2015). Together with our findings, these data indicate that activation of GLP-1Rs expressed in the VTA and lateral septum reduces the rewarding and reinforcing effects of cocaine.

The role of corticosterone in cocaine addiction is not entirely clear. The present results are consistent with previous studies demonstrating that cocaine self-administration is associated with increased plasma and central levels of corticosterone (Galici et al, 2000; Goeders and Guerin, 1996; Mantsch et al, 2000). It has been shown that systemic and intraaccumbens administration of corticosterone enhances/facilitates the acquisition of cocaine taking (Deroche et al, 1997; Goeders and Guerin, 1996) as well as the reinstatement of cocaine seeking (Graf et al, 2013). However, corticosterone may not be necessary for the on-going consumption of cocaine. Although administration of metyrapone, a corticosterone synthesis inhibitor, reduces maintenance of cocaine self-administration, these effects are not correlated with decreased plasma corticosterone levels (Goeders and Guerin, 2008; Guerin et al, 2014). Consistent with these results, adrenalectomy does not affect cocaine self-administration (Guerin et al, 2014). Our findings show that peripheral corticosterone administration increases activation of NTS GLP-1-producing neurons and that increased corticosterone signaling in the hindbrain decreases cocaine taking. These data clearly indicate that corticosterone signaling in the hindbrain/NTS functions to reduce the reinforcing efficacy of cocaine. Thus, the ability of central corticosterone to facilitate cocaine taking depends upon the neural circuits engaged and the stage of the addiction cycle (ie, acquisition $v s$ maintenance of cocaine taking).

\section{CONCLUSIONS}

The present findings demonstrate a novel role for central GLP-1Rs in cocaine self-administration and that cocaine taking putatively increases corticosterone-mediated activation of GLP-1-producing neurons in the NTS. This cocaine-induced increase in activation of NTS GLP-1-producing neurons that project to the VTA may represent a compensatory mechanism to reduce the reinforcing efficacy of cocaine. Thus, we have identified a novel circuit that functions as a 'brake' to reduce further cocaine consumption. Although activation of NTS GLP-1 projections to the VTA reduces the reinforcing efficacy of cocaine (present findings) and palatable food (Alhadeff $e t a l$, 2012), our findings indicate that lower doses of GLP-1R agonists are sufficient to selectively reduce cocaine taking. In addition to investigating the effects of GLP-1R agonists on cocaine reinforcement in humans, clinical trials will also have to determine the potential side effects of GLP-1 agonists in human cocaine addicts including effects on insulin secretion, blood glucose metabolism, and gastrointestinal function. Our findings provide support for further preclinical and clinical investigations aimed at exploring the ability of GLP-1R ligands to reduce cocaine use in human addicts.

\section{FUNDING AND DISCLOSURE}

The authors declare no conflict of interest.

\section{ACKNOWLEDGMENTS}

This work was supported by the following grants from the National Institutes of Health: K01 DA030445 and R01 DA037897 (to HDS), F32 DK097954 and K01 DK103804 (to EGM-B), T32 DA28874 (to LAG and MEW), T32 MH014654 (to DJR), and R01 DK096139 (MRH). HDS and KYI were partially supported by a Vagelos Undergraduate Research Grant from the Center for Undergraduate Research \& Fellowships at the University of Pennsylvania. We also thank Adrian Arreola, Christopher Turner, Nicole Hernandez, and Lauren McGrath for their technical assistance as well as Dr Kendra Bence for use of equipment and reagents.

\section{REFERENCES}

Alhadeff AL, Rupprecht LE, Hayes MR (2012). GLP-1 neurons in the nucleus of the solitary tract project directly to the ventral tegmental area and nucleus accumbens to control for food intake. Endocrinology 153: 647-658.

Arnold JM, Roberts DC (1997). A critique of fixed and progressive ratio schedules used to examine the neural substrates of drug reinforcement. Pharmacol Biochem Behav 57: 441-447.

Barrera JG, Jones KR, Herman JP, D'Alessio DA, Woods SC, Seeley RJ (2011). Hyperphagia and increased fat accumulation in two models of chronic CNS glucagon-like peptide-1 loss of function. J Neurosci 31: 3904-3913.

Buffalari DM, Rinaman L (2014). Cocaine self-administration and extinction alter medullary noradrenergic and limbic forebrain cFos responses to acute, noncontingent cocaine injections in adult rats. Neuroscience 281C: 241-250.

Buse JB, Rosenstock J, Sesti G, Schmidt WE, Montanya E, Brett JH et al (2009). Liraglutide once a day versus exenatide twice a day for type 2 diabetes: a 26-week randomised, parallel-group, multinational, open-label trial (LEAD-6). Lancet 374: 39-47.

Deroche V, Marinelli M, Le Moal M, Piazza PV (1997). Glucocorticoids and behavioral effects of psychostimulants. II: cocaine intravenous self-administration and reinstatement depend on glucocorticoid levels. J Pharmacol Exp Ther 281: 1401-1407.

Dickson SL, Shirazi RH, Hansson C, Bergquist F, Nissbrandt H, Skibicka KP (2012). The glucagon-like peptide 1 (GLP-1) analogue, exendin-4, decreases the rewarding value of food: a new role for mesolimbic GLP-1 receptors. J Neurosci 32: 4812-4820.

Egecioglu E, Engel JA, Jerlhag E (2013a). The glucagon-like peptide 1 analogue Exendin-4 attenuates the nicotine-induced locomotor stimulation, accumbal dopamine release, conditioned place preference as well as the expression of locomotor sensitization in mice. PLoS One 8: e77284.

Egecioglu E, Engel JA, Jerlhag E (2013b). The glucagon-like peptide 1 analogue, exendin-4, attenuates the rewarding properties of psychostimulant drugs in mice. PLoS One 8: e69010.

Egecioglu E, Steensland P, Fredriksson I, Feltmann K, Engel JA, Jerlhag E (2013c). The glucagon-like peptide 1 analogue Exendin4 attenuates alcohol mediated behaviors in rodents. Psychoneuroendocrinology 38: 1259-1270.

Engel JA, Jerlhag E (2014). Role of appetite-regulating peptides in the pathophysiology of addiction: implications for pharmacotherapy. CNS Drugs 28: 875-886.

Galici R, Pechnick RN, Poland RE, France CP (2000). Comparison of noncontingent versus contingent cocaine administration on plasma corticosterone levels in rats. Eur J Pharmacol 387: 59-62.

Goeders NE, Guerin GF (1996). Role of corticosterone in intravenous cocaine self-administration in rats. Neuroendocrinology 64: 337-348.

Goeders NE, Guerin GF (2008). Effects of the combination of metyrapone and oxazepam on cocaine and food selfadministration in rats. Pharmacol Biochem Behav 91: 181-189. 
Grabus SD, Glowa JR, Riley AL (2004). Morphine- and cocaineinduced c-Fos levels in Lewis and Fischer rat strains. Brain Res 998: 20-28.

Graf EN, Wheeler RA, Baker DA, Ebben AL, Hill JE, McReynolds JR et al (2013). Corticosterone acts in the nucleus accumbens to enhance dopamine signaling and potentiate reinstatement of cocaine seeking. J Neurosci 33: 11800-11810.

Graham DL, Erreger K, Galli A, Stanwood GD (2013). GLP-1 analog attenuates cocaine reward. Mol Psychiatry 18: 961-962.

Grill HJ, Hayes MR (2012). Hindbrain neurons as an essential hub in the neuroanatomically distributed control of energy balance. Cell Metabol 16: 296-309.

Gu G, Roland B, Tomaselli K, Dolman CS, Lowe C, Heilig JS (2013). Glucagon-like peptide-1 in the rat brain: distribution of expression and functional implication. J Comp Neurol 521: 2235-2261.

Guerin GF, Schmoutz CD, Goeders NE (2014). The extra-adrenal effects of metyrapone and oxazepam on ongoing cocaine selfadministration. Brain Res 1575: 45-54.

Gutzwiller JP, Drewe J, Goke B, Schmidt H, Rohrer B, Lareida J et al (1999a). Glucagon-like peptide-1 promotes satiety and reduces food intake in patients with diabetes mellitus type 2. Am J Physiol 276: R1541-R1544.

Gutzwiller JP, Goke B, Drewe J, Hildebrand P, Ketterer S, Handschin D et al (1999b). Glucagon-like peptide-1: a potent regulator of food intake in humans. Gut 44: 81-86.

Han VK, Hynes MA, Jin C, Towle AC, Lauder JM, Lund PK (1986). Cellular localization of proglucagon/glucagon-like peptide I messenger RNAs in rat brain. J Neurosci Res 16: 97-107.

Harasta AE, Power JM, von Jonquieres G, Karl T, Drucker DJ, Housley GD et al (2015). Septal glucagon-like peptide 1 receptor expression determines suppression of cocaine-induced behavior. Neuropsychopharmacology 40: 1969-1978.

Hayes MR, Bradley L, Grill HJ (2009). Endogenous hindbrain glucagon-like peptide-1 receptor activation contributes to the control of food intake by mediating gastric satiation signaling. Endocrinology 150: 2654-2659.

Hayes MR, De Jonghe BC, Kanoski SE (2010). Role of the glucagonlike-peptide-1 receptor in the control of energy balance. Physiol Behav 100: 503-510.

Hodos W (1961). Progressive ratio as a measure of reward strength. Science 134: 943-944.

Holland RA, Leonard JJ, Kensey NA, Hannikainen PA, De Jonghe BC (2014). Cisplatin induces neuronal activation and increases central AMPA and NMDA receptor subunit gene expression in mice. Physiol Behav 136: 79-85.

Holst JJ (2007). The physiology of glucagon-like peptide 1. Physiol Rev 87: 1409-1439.

Kanoski SE, Fortin SM, Arnold M, Grill HJ, Hayes MR (2011). Peripheral and central GLP-1 receptor populations mediate the anorectic effects of peripherally administered GLP-1 receptor agonists, liraglutide and exendin-4. Endocrinology 152: 3103-3112.

Kanoski SE, Rupprecht LE, Fortin SM, De Jonghe BC, Hayes MR (2012). The role of nausea in food intake and body weight suppression by peripheral GLP-1 receptor agonists, exendin-4 and liraglutide. Neuropharmacology 62: 1916-1927.

Kenny PJ (2011a). Common cellular and molecular mechanisms in obesity and drug addiction. Nat Rev Neurosci 12: 638-651.

Kenny PJ (2011b). Reward mechanisms in obesity: new insights and future directions. Neuron 69: 664-679.

Larsen PJ, Tang-Christensen M, Holst JJ, Orskov C (1997). Distribution of glucagon-like peptide-1 and other preproglucagonderived peptides in the rat hypothalamus and brainstem. Neuroscience 77: 257-270.

Lovshin JA, Drucker DJ (2009). Incretin-based therapies for type 2 diabetes mellitus. Nat Rev Endocrinol 5: 262-269.
Mantsch JR, Schlussman SD, Ho A, Kreek MJ (2000). Effects of cocaine self-administration on plasma corticosterone and prolactin in rats. J Pharmacol Exp Ther 294: 239-247.

Merchenthaler I, Lane M, Shughrue P (1999). Distribution of prepro-glucagon and glucagon-like peptide-1 receptor messenger RNAs in the rat central nervous system. J Comp Neurol 403: 261-280.

Mietlicki-Baase EG, Ortinski PI, Rupprecht LE, Olivos DR, Alhadeff AL, Pierce RC et al (2013). The food intakesuppressive effects of glucagon-like peptide-1 receptor signaling in the ventral tegmental area are mediated by AMPA/kainate receptors. Am J Physiol Endocrinol Metab 305: E1367-E1374.

Mietlicki-Baase EG, Reiner DJ, Cone JJ, Olivos DR, McGrath LE, Zimmer DJ et al (2015). Amylin modulates the mesolimbic dopamine system to control energy balance. Neuropsychopharmacology 40: 372-385.

Narayanan NS, Guarnieri DJ, DiLeone RJ (2010). Metabolic hormones, dopamine circuits, and feeding. Front Neuroendocrinol 31: 104-112.

Paxinos G, Watson C (1997). The Rat Brain in Stereotaxic Coordinates. Academic Press: New York.

Pierce RC, Kumaresan V (2006). The mesolimbic dopamine system: the final common pathway for the reinforcing effect of drugs of abuse? Neurosci Biobehav Rev 30: 215-238.

Richardson NR, Roberts DC (1996). Progressive ratio schedules in drug self-administration studies in rats: a method to evaluate reinforcing efficacy. J Neurosci Methods 66: 1-11.

Rinaman L (2010). Ascending projections from the caudal visceral nucleus of the solitary tract to brain regions involved in food intake and energy expenditure. Brain Res 1350: 18-34.

Ruttimann EB, Arnold M, Hillebrand JJ, Geary N, Langhans W (2009). Intrameal hepatic portal and intraperitoneal infusions of glucagon-like peptide-1 reduce spontaneous meal size in the rat via different mechanisms. Endocrinology 150: 1174-1181.

Schmidt HD, Anderson SM, Famous KR, Kumaresan V, Pierce RC (2005). Anatomy and pharmacology of cocaine priming-induced reinstatement of drug seeking. Eur J Pharmacol 526: 65-76.

Schmidt HD, Famous KR, Pierce RC (2009). The limbic circuitry underlying cocaine seeking encompasses the PPTg/LDT. Eur J Neurosci 30: 1358-1369.

Secher A, Jelsing J, Baquero AF, Hecksher-Sorensen J, Cowley MA, Dalboge LS et al (2014). The arcuate nucleus mediates GLP-1 receptor agonist liraglutide-dependent weight loss. J Clin Invest 124: 4473-4488.

Shirazi RH, Dickson SL, Skibicka KP (2013). Gut peptide GLP-1 and its analogue, Exendin-4, decrease alcohol intake and reward. PLoS One 8: e61965.

Shukla AP, Buniak WI, Aronne LJ (2015). Treatment of obesity in 2015. J Cardiopulm Rehabil Prev 35: 81-92.

Sisley S, Gutierrez-Aguilar R, Scott M, D'Alessio DA, Sandoval DA, Seeley RJ (2014). Neuronal GLP1R mediates liraglutide's anorectic but not glucose-lowering effect. J Clin Invest 124: 2456-2463.

Skibicka KP (2013). The central GLP-1: implications for food and drug reward. Front Neurosci 7: 181.

Turton MD, O'Shea D, Gunn I, Beak SA, Edwards CM, Meeran K et al (1996). A role for glucagon-like peptide-1 in the central regulation of feeding. Nature 379: 69-72.

Williams KW, Elmquist JK (2012). From neuroanatomy to behavior: central integration of peripheral signals regulating feeding behavior. Nat Neurosci 15: 1350-1355.

Zahm DS, Becker ML, Freiman AJ, Strauch S, Degarmo B, Geisler S et al (2010). Fos after single and repeated self-administration of cocaine and saline in the rat: emphasis on the basal forebrain and recalibration of expression. Neuropsychopharmacology 35: 445-463.

Zhang R, Packard BA, Tauchi M, D'Alessio DA, Herman JP (2009). Glucocorticoid regulation of preproglucagon transcription and RNA stability during stress. Proc Natl Acad Sci USA 106: 5913-5918. 